\title{
MEIOS ALTERNATIVOS DE SOLUÇÃO DE CONFLITO: ESTUDO DAS SOCIEDADES PRIMITIVAS E O NOVO CÓDIGO DE PROCESSO CIVIL
}

\section{ALTERNATIVE WAYS OF CONFLICT SOLVING: A STUDY OF PRIMITIVE SOCIETIES AND THE BRAZILIAN NEW CODE OF CIVIL PROCEDURE}

\author{
LUdmila Apoliano Gomes AlbuQUerQue \\ Doutora. Professora na Universidade Estadual Vale do Acaraú (UVA), Sobral, CE, Brasil.
}

ludmilaapoliano@hotmail.com

Gabrielle Apoliano Gomes Albuquerque Pearce

Mestranda do Programa de Pós Graduação em Direito pela Faculdade 7 de Setembro (Fa7), Fortaleza, CE, Brasil. gabrielle_apoliano@hotmail.com

\begin{abstract}
RESUMO
Ao estudar as sociedades primitivas percebe-se a presença dos meios alternativos de solução de conflito, apesar da ausência de positivação. O chefe indígena era o líder do grupo que deveria ter boa oratória, generosidade e ser moderador. Não podia repelir um conflito levado a ele, competindo manter a paz e a harmonia. Desta forma, o presente artigo objetiva investigar a importância dos meios de solução de conflitos e a sua existência desde as sociedades primitivas, revelando-os não como inovação jurídica, mas sim já presente nas antigas sociedades. E, ainda, apresentar as disposições trazidas pelo novo Código de Processo Civil de 2015 com relação a estes meios. A natureza da pesquisa é qualitativa, lidando com os fatos sociais, teórica, através de fontes bibliográficas, e descritiva, com os fenômenos como vistos pelo pesquisador, através do método hipotético-dedutivo. A importância do tema revela-se na existência dos meios de solução de conflito desde antes de sua positivação.
\end{abstract}

Palavras-chave: chefe indígena; meios alternativos; sociedades primitivas.

\begin{abstract}
By studying primitive societies we can perceive the presence of alternative ways of conflict resolution, despite the lack of legal regulation. The aboriginal chief was the group leader who should have good oratory, generosity and be moderator. He could not repel a conflict led to him, always maintaining peace and harmony. Thus, this paper aims to investigate the importance of conflict resolution ways and their existence since primitive societies, showing them not as a legal innovation, but as something already present in ancient societies. It also presents the rules introduced by the Brazilian new Code of Civil Procedure of 2015 with respect to these means. The nature of the research is qualitative, dealing with social facts, theoretical, through literature sources, and descriptive, with the phenomena as seen by the researcher through the hypothetical-dedutive method. The importance of this issue reveals itself in the existence of conflict resolution ways before its legal provision.
\end{abstract}

Keywords: aboriginal chief; alternative ways; primitive societies. 


\section{SUMÁRIO}

INTRODUÇÃO; 1 SOCIEDADES PRIMITIVAS; 2 O CHEFE INDÍGENA; 3 MEIOS ALTERNATIVOS DE SOLUÇÃO DE CONFLITOS; 3.1 Conciliação; 3.2 Mediação; 3.3 Arbitragem; 4 NOVO CÓDIGO DE PROCESSO CIVIL E OS MEIOS DE SOLUÇÃO DE CONFLITO; CONCLUSÃO; REFERÊNCIAS.

\section{INTRODUÇÃO}

As sociedades primitivas eram comunidades antigas sem legislação ou normas positivadas que impusesse regras e condutas de como os indivíduos deveriam reger suas relações. Apesar de não-escrita, haviam normas de convivência no grupo que regia a convivência entre eles.

Nas sociedades indígenas havia um líder chamado de chefe indígena, considerado o moderador da comunidade, devendo possuir as qualidades de ser bom orador e generoso. Este atuava em nome da sociedade e não com base em decisões tomadas somente por ele. Desta forma, era uma espécie de representante da comunidade.

O chefe indígena ainda possuía a atribuição de mediar os conflitos a ele trazidos sem poder recusar esta atribuição. Atua como um terceiro que intermedia a lide na busca de uma solução.

Um terceiro intermediando um conflito visando à resolução do mesmo sem utilizar o judiciário para tal a fim é a finalidade dos meios alternativos de solução de conflito que é um instituto recente no ordenamento jurídico. Contudo, percebem-se características deste instituto nas sociedades primitivas.

Desta forma, a presente pesquisa pretende estudar se os meios alternativos de solução de conflito já existiam desde as sociedades primitivas. A importância da pesquisa é demonstrada através da necessidade de compreensão quanto à relevância do assunto, mostrando a importância das sociedades primitivas na formação de institutos presentes no ordenamento jurídico atual.

O objetivo deste artigo é demonstrar se havia a presença dos meios alternativos de solução de conflito nas sociedades primitivas, estudando a função do chefe indígena e se é similar a do terceiro que intermedia as lides, apresentando quais são estes meios e ainda qual sua previsão no ordenamento jurídico, em especial no Novo Código de Processo Civil de 2015 (NCPC/2015).

A metodologia utilizada nesta pesquisa é qualitativa, visto que se preocupa com os fatos sociais. Ainda, é teórica tendo em vista que utiliza fontes bibliográficas, a exemplo de livros, 
periódicos e consulta á internet e utiliza do método hipotético-dedutivo, partindo de uma ideia geral para individual que serão confirmadas ou não através de um teste de falseabilidade, por meio de uma pesquisa descritiva, somente descrevendo os fenômenos pesquisados sem demonstrar soluções.

Inicialmente analisam-se as sociedades primitivas e após estuda-se o chefe indígena. Ainda, apresentam-se os meios de solução extrajudicial de conflito e suas espécies, e a previsão destes no Novo Código de Processo Civil de 2015 (NCPC/2015).

\section{SOCIEDADES PRIMITIVAS}

Nas sociedades primitivas existia uma estrutura social onde "os seres humanos individuais, unidades essenciais neste caso, estão relacionados por uma série definida de relações sociais num todo integrado". Estas relações constituem a vida social que é considerada "o funcionamento da estrutura social". 1

Nesta vida social não havia legislação regendo as condutas do grupo. Os costumes eram considerados leis entre os mesmos. Apesar disso, constatava-se a indícios de um instituto presente no ordenamento jurídico que são os meios alternativos de solução de conflito: a conciliação, a mediação e a arbitragem. Estes meios são fenômenos sociais que "são consequência da estrutura social pela qual estão unidos". ${ }^{2}$

Dentro da estrutura social das sociedades primitivas está o chefe indígena que tinha um papel de liderança frente a comunidade atendendo aos anseios do grupo. Um de suas atribuições era atuar na solução de lides a ele apresentados, agindo então como um terceiro auxiliando na resolução do conflito.

Este não exercia poder frente à população, pois a ausência do estado é peculiaridade deste tipo de sociedade. Ainda, não tinham lei que a regulasse, são consideradas sociedades sem escrita. Desta forma, estão sempre privadas de algo, incompletas, não sendo verdadeiras sociedades. Após o estudo destas sociedades percebe-se que o destino de toda sociedade é o Estado.

Contudo, algumas comunidades permaneceram selvagens, e uma das explicações é porque estas sociedades baseiam-se na economia de subsistência. Não eram produzidos

\footnotetext{
1 RADCLIFFE-BROWN, Alfred Reginald. Estrutura e função na sociedade primitiva. Petrópolis: Vozes, 1881. P. 222-223.

2 RADCLIFFE-BROWN, Alfred Reginald. Estrutura e função na sociedade primitiva. Petrópolis: Vozes, 1881. p. 235.
} 
excedentes, logo ignoravam a economia de mercado e a concorrência. Visam o mínimo necessário à sobrevivência. Eles possuíam boas técnicas na fabricação de instrumentos e invenções que eram utilizadas para sua subsistência e também tinham qualidade de atividade técnica semelhante a sociedade industrial e técnica. Logo, a escolha de adotar uma economia de subsistência não é em razão da falta de habilidade técnica. Conclui-se deste fato que todo grupo humano chega, forçosamente, a exercer o mínimo necessário de domínio sobre o meio que ocupa. ${ }^{3}$

A produção de excedentes era possível na economia destes povos, mas o selvagem não saberia que destinação a dar e o resultado seria o consumo pelo resto do grupo. Então, a riqueza produzida por um seria consumida pelos demais caracterizando auto exploração da comunidade. ${ }^{4}$ Ou seja, todos os produtos produzidos pertencem a todos da comunidade. Desta forma, se alguém produz em excesso outro seria beneficiado com o excedente. Assim, haveria injustiça entre as pessoas da sociedade, onde uma das características era a solidariedade.

\section{CHEFE INDÍGENA}

As sociedades primitivas não possuem órgãos separados do poder político, o poder está junto à sociedade. ${ }^{5}$ Esta ausência de divisão demonstra que cada indivíduo tem uma importância dentro do grupo, onde o poder de gerir a comunidade é de todos, havendo um moderador, o chefe indígena, que auxilia nesta atribuição. Mas, na verdade, todos possuem o poder.

Ainda, não havia a sobreposição de um indivíduo sobre o outro, todos viviam em colaboração visando à coletividade, trabalhando em favor do grupo.

Por isso, o chefe indígena, que era o líder do grupo, era necessariamente o moderador do grupo, não podendo rejeitar as solicitações de seus administrados e ainda deveria ser um bom orador. $^{6}$

Este líder era responsável por transmitir a vontade da sociedade, possuindo a atribuição de ser porta voz do grupo, não possuindo qualquer tipo de poder ou soberania individualmente falando. Estas características eram necessárias, pois reflete o caráter solidário destas

3 CLASTRES, Pierre. A sociedade contra o Estado: investigações de antropologia política. Porto: Afrontamento, 1975. p.183-185.

${ }^{4}$ CLASTRES, Pierre. A arqueologia da violência. São Paulo: Ed. Cosac \& Naify, 2004. p. 175.

${ }_{6}^{5}$ Ibidem. p. 100.

6 CLASTRES, Pierre. A sociedade contra o Estado: investigações de antropologia política Porto: Ed. Afrontamento, 1975. p. 27. 
populações, devendo o líder manter atributos e consequentemente agindo para preservar este aspecto nas sociedades primitivas.

Ainda, compete ao chefe indígena manter a paz e a harmonia do grupo, abrandando as desavenças não pela utilização da força, visto que não possui este direito e nem seria reconhecida, mas devem atuar somente com seu prestígio, imparcialidade e palavra. Age mais que um juiz que sanciona, e sim como um árbitro que busca reconciliar. Possui como característica a generosidade, refletindo um dever de servidão, incompatível com avareza e o poder. $^{7}$

Isto visava evitar problemas dentro do grupo, por isso tamanha importância das atribuições do chefe indígena:

0 chefe é um "fazedor de paz" por excelência: é ele quem apazigua os possíveis conflitos que podem colocar em risco o seu grupo; o chefe deve ser generoso com seus bens: portanto, longe de ser alguém que manda seus subordinados trabalharem para poder gozar do ócio, é o chefe quem tem que trabalhar mais na comunidade, já que seu prestígio depende da sua generosidade; e somente um bom orador pode ser digno de ser chefe. ${ }^{8}$

Logo, o chefe indígena atua perante aos membros do grupo como um árbitro que visava solucionar os conflitos através do diálogo, sem o uso da força ou qualquer meio coercitivo. E apesar da ausência de soberania, o respeito dos outros perante o chefe indígena era reflexo de sua cultura.

A chefia não era considerada como um lugar de poder, nem reflexo de autoridade, poder de coerção ou de dar uma ordem. Ainda, não é visto como um comandante nem autoridade, as pessoas não devem obediência a ele. ${ }^{9}$ É alguém que auxilia a manter a paz e harmonia no grupo.

As atribuições do chefe indígena nas sociedades primitivas assemelham-se a do árbitro diante da arbitragem, qual seja resolver os conflitos que possam surgir entre os indivíduos sem utilização da força ou coerção, mas apenas do prestígio, em busca de convencer ao entendimento, não tendo sua palavra força de lei. ${ }^{10}$ Característica esta similar ao previsto na Lei

\footnotetext{
${ }^{7}$ Ibidem. p. 28-29.

${ }^{8}$ FERREIRA, Tatiana Amaral Sanches Ferreira. A antropologia de Pierre Clastres em crônicas dos índios Guayaki: o que sabem os Aché, caçadores nômades do Paraguai. Revista de Antropologia Social dos Alunos do PPGAS-UFSCar, v. 3, n. 1, jan-jun., p. 375-383, 2011. p. 376.

9 CLASTRES, Pierre. A sociedade contra o Estado: investigações de antropologia política Porto: Ed. Afrontamento, 1975. p.198-199.

${ }^{10}$ Ibidem. p.199-200.
} 
$\overline{\text { de Arbitragem ao estipular que as partes têm a faculdade de recorrer ao Judiciário para resolver }}$ o conflito.

O chefe selvagem possui várias tarefas dentro da sociedade sendo uma espécie de funcionário, falando em nome da sociedade em determinadas circunstâncias como liderar operações de guerra. Comparando com a ordem jurídica atual, a atuação em guerra assemelhase a de um Ministro de Estado, mas com a diferença fundamental que as decisões tomadas pelo chefe são desejos da tribo e não uma tática determinada individualmente. As negociações e vontade de guerrear só ocorrem quando a sociedade assim deseja, sendo o chefe um mensageiro da vontade da sociedade. ${ }^{11}$

Uma das características que difere o desempenho de chefe indígena de um cargo de poder é que a liderança reflete os desejos da sociedade. Então, o chefe atua em nome da coletividade. Em um cargo de poder as atuações são reflexo de uma decisão tomada individualmente.

Estas tarefas designadas ao chefe conferem a ele a qualidade de subordinado, devendo manter as expectativas do grupo sob pena de ser substituído e até morto. Assim, na verdade, ele está dependente da sociedade e a recíproca é verdadeira, pois o povo precisa ser representado e o representante necessita suprir as imposições postas a ele. ${ }^{12}$

Como o líder pratica seus atos com base nos anseios da sociedade ele age de acordo com os desejos do grupo. Logo, o grupo determinada como o chefe indígena deve agir ao representar a sociedade. Assim, aparenta tratar-se um de uma espécie de empregado deste grupo.

\section{MEIOS ALTERNATIVOS DE SOLUÇÃO DE CONFLITOS}

O efetivo acesso à justiça é um princípio consagrado na Constituição Federal de 1988 (CF/88), representando um avanço frente às dificuldades vivenciadas na prática para garantia deste direito.

A situação econômica é um dos obstáculos à efetivação deste princípio, tendo em vista os custos elevados do processo judicial, além da necessidade de pagamento de honorários

\footnotetext{
${ }_{11}^{11}$ CLASTRES, Pierre. A arqueologia da violência. São Paulo: Ed. Cosac \& Naify, 2004. p.102-103.

12 RODRIGUES, Amanda; THEMUDO, Thiago. Sociedades primitivas e direito contemporâneo: de que forma a justiça tribal pode nos ajudar a repensar a nossa justiça. Revista Brasileira de Políticas Públicas, Brasília, v. 5, no 1, p. 308, jan/jun. 2015.
} 
advocatícios e eventuais despesas se necessárias como exemplo honorários periciais e taxas cartorárias. Além deste, o desconhecimento dos direitos previstos no ordenamento jurídico faz com que as pessoas não visem reivindica-los. ${ }^{13}$

0 viés financeiro é um das razões para não buscar o judiciário para a solução de uma lide. Apesar de ser garantido aos pobres na forma da lei a gratuidade da justiça a simples declaração não é suficiente para receber este direito, devendo enquadrar-se nos requisitos que a lei estipula.

A falta de conhecimento sobre a legislação está diretamente ligado ao exercício do direito constitucional de acesso à justiça. Por não ter conhecimento da lei, o indivíduo não ingressa requerendo o que the é de direito e resta prejudicada sua garantia de acesso à justiça. Por isso, a divulgação e esclarecimento com relação as normas legais auxilia na efetivação deste direito.

Frente a estes obstáculos, há falha na prestação jurisdicional o que motiva as partes a buscarem formas alternativas de solução de conflitos, que possuem como características a cooperação, a confidencialidade, a ênfase no futuro e a economia de dinheiro, tempo e energia. $^{14}$

Com o objetivo de suprir questões, os meios alternativos de solução de conflitos visam à solução dos litígios de maneiras diversa do processo civil tradicional, mas seguindo os mesmos princípios.

Através da utilização destes meios há diversos benefícios como agilidade na solução da lide, redução de despesas com o conflito e satisfação quanto ao resultado da lide, visto que as partes atuam diretamente em sua solução.

\subsection{Conciliação}

Este método utiliza um terceiro que não impõe e não vincula as partes, não necessitando ter um conhecimento aprofundado do caso em litígio, mas sim objetiva a reunião

\footnotetext{
${ }^{13}$ MARASCA, Elisângela Nedel. Meios alternativos de solução de conflitos como forma de acesso à justiça e efetivação da cidadania. Revista Direito em Debate, ljuí, ano XV n 27, 28, jan-jun/jul-dez. 2007. p. 42.

${ }^{14}$ KLUNK, Luzia. O conflito e os meios de solução: reflexões sobre mediação e conciliação. In: SPLENGER, Fabiana Marion; SPLENGER NETO, Theobaldo (Orgs.) Mediação enquanto política pública: o conflito, a crise da jurisdição e as práticas mediativas. Santa Cruz do Sul: EDUNISC - Editora UNISC, 2012. p. 77.
} 
dos litigantes para finalizar um conflito evitando uma possível demanda, com uma participação ativa, mas moderada. ${ }^{15}$

O conciliador tem por finalidade unir as partes para solução do conflito sem sua intervenção, apenas aproximando os interessados sem apresentar qualquer decisão para o litígio em análise, atuando com posição neutra. Formam uma relação triangular em que este terceiro auxilia na composição. Ele não precisa ter um conhecimento aprofundado no conflito, pois este será resolvido por consenso entre os litigantes. ${ }^{16}$

Não há necessidade de conhecimento jurídico aprofundado visto que não irá decidir a lide, partes que atuarão neste sentido.

Em diversas jurisprudências é possível perceber a importância da conciliação perante o Judiciário, respeitando e protegendo:

RECURSO DE REVISTA. COMISSÃO DE CONCILIAÇÃO PRÉVIA. CONCILIAÇÃO EXTRAJUDICIAL. EFICÁCIA LIBERATÓRIA GERAL. AUSÊNNCIA DE RESSALVA. Dispõe o art. 625-E, parágrafo único, da CLT que o termo de conciliação firmado perante a Comissão de Conciliação Prévia é título executivo extrajudicial e terá eficácia liberatória geral, exceto quanto às parcelas nele expressamente ressalvadas. $\mathrm{Na}$ hipótese dos autos, o Tribunal Regional não registra a existência de ressalvas no termo de conciliação lavrado, tampouco the atribuiu eficácia liberatória geral. Esse entendimento conflita com a norma inserta no mencionado art. 625-E, parágrafo único, da CLT. Recurso de revista conhecido e provido. (TST - RR: 18165320115040403, Relator: Walmir Oliveira da Costa, Data de Julgamento: 17/02/2016, $1^{\mathrm{a}}$ Turma, Data de Publicação: DEJT 19/02/2016). ${ }^{17}$

A aceitação da conciliação pelo Judiciário ocorre desde aquela realizada extrajudicialmente, como no exemplo apresentado na jurisprudência em que há respeito à conciliação extrajudicial realizada perante a comissão de conciliação prévia, vindo a ser prevista esta modalidade de solução de conflito em legislação como forma de confirmar sua aceitação no mundo jurídico.

\footnotetext{
${ }^{15}$ BRAGA NETO, Adolfo. A mediação de conflitos e suas diferenças com a conciliação. Disponível em: < http://www.cnj.jus.br/images/programas/movimento-pela-

conciliacao/arquivos/ARTIGO\%20Adolfo_MEDIACAO_CONCILIACAO_FEV_20111.pdf> Acesso em: 03 abr. 2016. p-1.

${ }^{16}$ Ibidem.

17 BRASIL. Tribunal Superior do Trabalho. Ementa de decisão que deu provimento a pedido de reconhecimento de termo de conciliação lavrado. Recurso de revista $n^{\circ}$ 18165320115040403. Ete engenharia de telecomunicações e eletricidade Ltda, Daniel Ramos, Oi s/a e Alcatel-lucent Brasil s/a. Relator: Walmir Oliveira da Costa. 17 de fev. De 2016. Disponível em: < http://tst.jusbrasil.com.br/jurisprudencia/307140214/recurso-de-revista-rr-18165320115040403>. Acesso em: 29 jul. 2016.
} 
Ressalta-se que a origem do termo conciliação é proveniente da palavra em latim “conciliabulum”, que na Antiga Roma possui o significado de um local para se buscar um acordo. ${ }^{18}$ Ou seja, a origem do nome sugere a função que the é atribuído que é a solução do conflito através da concordância entre as partes.

\subsection{Mediação}

$\mathrm{Na}$ mediação, o mediador busca ajudar as partes omitindo-se de expressar opinião ou juízo de valor, devendo somente proporcionar as partes a abordar sobre os problemas do conflito, dialogando e assim concluírem em uma solução. ${ }^{19}$

A mediação é instituto semelhante à conciliação, porém a diferença é que o mediador tem uma posição menos ativa, visando que as partes busquem sozinhas encontre a solução para o caso em tela.

Neste instituto, o estabelecimento do vínculo de confiança entre as partes e o mediador, denominado rapport, é um elemento que reflete a característica de facilitador de comunicação entre as partes. É uma qualidade que o diferencia do juiz, onde há a centralidade do poder. ${ }^{20}$

A mediação facilita a solução do conflito por meio de um terceiro que intermedia o conflito semelhante à atuação do magistrado, contudo posiciona-se em situação de igualdade entre as partes e não com superioridade, o que transmite confiança para buscar auxílio com o mediador.

Ainda, a mediação garante aos indivíduos a possibilidade de solução do seu próprio conflito oportunizada através da comunicação entre as partes envolvidas compartilhando sentimentos, problemas, possíveis soluções e mudanças de atitudes para a pacificação do problema.

\footnotetext{
${ }^{18}$ BRAGA NETO, Adolfo. A mediação de conflitos e suas diferenças com a conciliação. Disponível em: < http://www.cnj.jus.br/images/programas/movimento-pela-

conciliacao/arquivos/ARTIGO\%20Adolfo_MEDIACAO_CONCILIACAO_FEV_20111.pdf>. Acesso em: 03 abr. 2016. p-1.

19 REIS, Marcos Aurélio; COUTINHO, Patrícia Martins Rodrigues. A prática da mediação e o acesso à justiça: por um Agir Comunicativo. Disponível em: < file:///C:/Users/User/Downloads/ARTIGOCIENTIFICO_MEDIACAOUNIEURO.pdf>. Acesso em: 03 abr. 2016. p-17.

${ }_{20}$ MELLO, Kátia Sento Sé; BAPTISTA, Bárbara Gomes Lupetti. Mediação e Conciliação no Judiciário: Dilemas e significados. Disponível em: <http://www.uff.br/ineac/sites/default/files/mediacaoconciliacao--judiciario_dilemas_e_significados.pdf>. Acesso em: 03 abr. 2016. p-10-11.
} 


\subsection{Arbitragem}

Este meio de solução de conflito difere-se a conciliação e mediação, pois o árbitro, terceiro que intermedia o caso, pode tomar uma decisão frente ao problema a ele apresentado, assemelhando sua atuação com a função judicial.

Contudo, diferencia-se por ser mais ágil, sigiloso e menos onerosa, mostrando-se uma possibilidade de não recorrer ao poder judiciário que geralmente caracteriza-se pela lentidão e de alto custo. ${ }^{21}$ Assim, a arbitragem é um processo hetecompositivo, visto que um terceiro analisará e julgará o caso a ele apresentado, atuação similar a atribuição do magistrado, enquanto a conciliação e medição são meios de autocomposição, onde as partes apresentam a solução para o caso.

Frente à vagarosidade do judiciário, os meios alternativos de solução de conflitos apresentam-se uma saída para não enfrentar esta demora. Em especial a arbitragem possui similaridade com a atuação do poder judiciário, onde se ressalta a existência uma lei que regula a arbitragem, a Lei $n^{\circ} 9307 / 96$, que estipula os requisitos em que pode ocorrer e como deve acontecer.

A arbitragem é aceita pelo poder judiciário, o qual reconhece sua importância respeitando os requisitos, como exemplo na proibição do árbitro ser escolhido por apenas uma das partes:

OGMO. ARBITRAGEM. Não se pode admitir que a escolha do árbitro fique a cargo apenas de uma das partes envolvidas. O legislador estabeleceu o critério da concordância de ambos os interessados, de sorte que a não observância desse preceito importa inválido o procedimento de arbitragem adotado. Inteligência do parágrafo $3^{\circ}$, do art. 37 , da Lei $n^{\circ} 12.518 / 2013$. Recurso ordinário a que se nega provimento. (TRT-2 - RO: 8972120135020 SP 00008972120135020445 A28, Relator: NELSON NAZAR, Data de Julgamento: 11/02/2014, $3^{\text {a }}$ TURMA, Data de Publicação: 19/02/2014). ${ }^{22}$

Ressalta-se que apesar de haver estas espécies, ainda é necessário disseminar a cultura dos meios alternativos de solução de conflito, tornando-os público e esclarecendo suas

\footnotetext{
${ }^{21}$ REIS, Ívano de Menezes; HOGEMANN, Edna Raquel; MACHADO, Consuêlo de Freitas. Arbitragem: noções essenciais - entendendo a Lei $n^{\circ}$ 9307/96. Revista eletrônicada UCB. Brasília, p. 202-252. Disponível em: <http://www.castelobranco.br/sistema/novoenfoque/files/04/REVISTA_ELETRONICA_DE_DIREITO_DA_UC B-ARBITRAGEM_NOCOES_ESSENCIAIS.pdf>. Acesso em: 20 maio 2016.

${ }^{22}$ BRASIL. Tribunal Regional do Trabalho da $2^{\text {a }}$ Região. Ementa de decisão que negou provimento ao pedido sobre escolha de árbitro. Recurso ordinário $n^{\circ} 8972120135020$ SP 00008972120135020445 A28. Órgão gestor de mão de obra do Porto de Santos e Marcos César dos Santos. Relator: Nelson Nazar. 19 de fev. de 2014. Disponível em: <http://trt-2.jusbrasil.com.br/jurisprudencia/25001118/recurso-ordinarioro-8972120135020-sp-00008972120135020445-a28-trt-2>. Acesso em: 29 jul. 2016.
} 
vantagens, visto que é um modo de auxiliar na atuação do poder judiciário e traz benefício às partes.

\section{NOVO CÓDIGO DE PROCESSO CIVIL E OS MEIOS DE SOLUÇÃO DE CONFLITO}

Dentre as disposições trazidas pelo Novo Código de Processo Civil de 2015 (NCPC/2015), há a delimitação da conciliação e mediação, ressaltando assim a importância destes na solução dos casos. A arbitragem, já regulada por lei própria, também é valorizada por este novo código, contudo inovações legislativas referem-se à conciliação e mediação. Ainda, destaca-se o dever destes institutos serem estimulados pelos envolvidos no processo judicial.

Assim, os conciliadores e mediadores judiciais são figuras auxiliares da Justiça de acordo com o NCPC/2015. ${ }^{23}$ A remuneração destes deverá ser feita pelo tribunal, conforme estabelecer o Conselho Nacional de Justiça, e quando houver gratuidade, certamente recairá a obrigação ao poder público, pois este não tem a faculdade de oferecer a conciliação e mediação. ${ }^{24}$

Ressalta-se que não se trata de inovações de instrumento de meios de solução de conflito, mas apenas da novidade quanto à sua positivação. Pois estes meios apresentam sinais de existência desde as sociedades primitivas, em especial, na figura do chefe indígena, como já explanado.

Estes meios são considerados novidades, mas já presente das sociedades antigas, visto que "durante um longo período, os métodos informais de solução das controvérsias foram considerados próprios das sociedades primitivas e tribais, enquanto o processo jurisdicional representava insuperável conquista da civilização". ${ }^{25}$

O artigo 165 e seguintes do NCPC/2015 determinam a criação de centros judiciários de solução consensual de conflitos. E ainda, elenca os princípios a serem seguidos, quais sejam, da independência, da imparcialidade, da autonomia da vontade, da confidencialidade, da

\footnotetext{
${ }^{23}$ BUENO, Cassio Scarpinella. Novo Código de Processo Civil anotado. São Paulo: Saraiva, 2015. p. 150151.

${ }^{24}$ SILVA, Sílvio Maia da. O novo Código de Processo Civil e a mediação como meio de solução de controvérsias. 2015.2 Disponível em: http://www5.tjba.jus.br/conciliacao/images/stories/O_Novo_CPC_e_a_Medicao.pdf>. Acesso em: 24 maio 2016. p. 4.

${ }^{25}$ GRINOVER, Ada Pellegrini. Novas tendências do direito processual. Malheiros: São Paulo, 2008. p. 216.
} 
oralidade, da informalidade e da decisão informada e também as atribuições dos conciliadores e mediadores.

Esta determinação pode ser considerada um excesso visto que não se trata de uma norma processual e sim da competência de organização judiciária, demonstrando a intenção do legislador em estipular uma nova cultura. Assim, apresenta uniformidade e consistência nos estados da federação. ${ }^{26}$

Este novo código estipulou como requisito da petição inicial a opção do autor pela realização ou não de audiência de conciliação ou de mediação, conforme previsto no inciso VII do artigo 319.

Outra inovação é com relação às ações de família, em que devem ser feitos esforços para que haja a solução consensual do caso, inclusive extrajudicial, previsão do artigo 694 do NCPC/2015. Além disto, há a obrigatoriedade da audiência de conciliação em todos os casos (art. 334 do NCPC/2015).

Haverá a possibilidade de dispensa desta audiência somente após justificativa clara e precisa dos motivos pelos quais esta não deve acontecer. Apresentado o pedido, o magistrado analisará o requerimento, que poderá ser considerado abuso de direito de ação e ter o processo extinto sem julgamento do mérito ou indeferimento da petição inicial por falta de interesse de agir. ${ }^{27}$

As estipulações do NCPC/2015 visam que a decisão proferida pelo magistrado seja uma das últimas saídas para solucionar o conflito apresentado ao judiciário, defendendo a utilização de mecanismos alternativos de solução de conflitos para resolver o caso. ${ }^{28}$ Desta forma, as partes buscam a melhor maneira de decidir a lide com base em seus anseios e evita a intervenção judicial.

Analisando a atribuição do magistrado paralelamente com a do chefe indígena nas sociedades primitivas, percebe-se que exercem papeis semelhantes, contudo, à época destas

${ }^{26}$ SILVA, Sílvio Maia da. O novo Código de Processo Civil e a mediação como meio de solução de

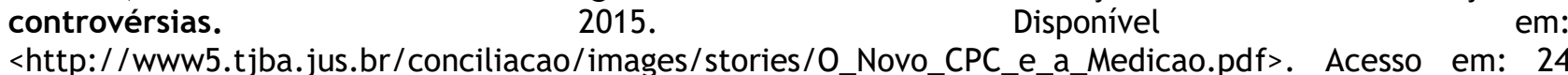
maio 2016. p.3.

${ }^{27}$ SOUZA, Victor Roberto Corrêa de. O novo código de processo civil brasileiro e a audiência de conciliação ou mediação como fase inicial do procedimento. In: MALLART, Adriana Silva; DIZ, Jamile Bergamaschine Mota; GAGLIETTI, Mauro José. (Orgs.) Justiça mediática e preventiva. Florianópolis: CONPEDI, 2015. p. 282.

${ }^{28}$ SOUZA, Victor Roberto Corrêa de. O novo código de processo civil brasileiro e a audiência de conciliação ou mediação como fase inicial do procedimento. In: MALLART, Adriana Silva; DIZ, Jamile Bergamaschine Mota; GAGLIETTI, Mauro José. (Orgs.) Justiça mediática e preventiva. Florianópolis: CONPEDI, 2015. p. 262. 
sociedades não havia legislação tratando desta competência ao chefe, ao contrário do que se observa atualmente, em que o NCPC/2015 estipula expressamente as atribuições de conciliação no processo judicial, como se percebe com a obrigatoriedade da realização de audiência de conciliação.

\section{CONCLUSÃO}

O termo "sociedades primitivas" leva a crer que se trata do estudo de sociedades ultrapassadas quando na verdade nela haviam institutos considerados inovadores pelo ordenamento jurídico. Estudando estas sociedades percebe-se que diversos institutos considerados inovadores no atual ordenamento jurídico, na verdade, já estavam presente apesar de não estarem previstas em legislações.

A figura de um terceiro, seja conciliador, mediador ou árbitro, era presente nestas sociedades através do chefe indígena que deveria ter as qualidades de boa oratória, generosidade e ser um moderador do grupo, não podendo esquivar-se de qualquer caso que tivesse que intermediar.

Desta forma, percebe-se que estas sociedades não são ultrapassadas, pelo contrário, desenvolveram meios de lidar com os conflitos sem conhecimento jurídico, similar ao caminho encontrado pelos legisladores para resolver os problemas. Mas estes alcançaram após estudos e análises. Assim, importante é o estudo destas sociedades, pois se percebe que os meios alternativos de solução de conflitos existem mesmo antes de sua previsão legal, apesar de não positivados.

Outras inovações jurídicas podem ter indícios de existência desde sociedades como as primitivas, contudo por considerá-las arcaicas não são estudadas. Frente a isto, demonstra-se a importância de pesquisar sobre os grupos antigos e a possibilidade de descobrir indícios de institutos presente na legislação atual.

O Novo Código de Processo Civil de 2015 (NCPC/2015) apenas determinou em seu texto a possibilidade e obrigatoriedade destes meios alternativos de solução de conflito não se tratando de fato de uma inovação, visto que estes institutos já eram utilizados extrajudicialmente, como por exemplo, através das comissões de conciliação prévia, núcleos de mediação e conciliação e arbitragem.

Ainda, eram utilizados antes da positivação de qualquer destas espécies mencionadas, visto que já existiam desde as sociedades primitivas. Ressalta-se que não com tantas regras e 
normas, mas sim de uma forma mais singela, o que não difere o objetivo final buscado: solucionar o conflito entre as partes.

\section{REFERÊNCIAS}

BRAGA NETO, Adolfo. A mediação de conflitos e suas diferenças com a conciliação. Disponível em: <http://www.cnj.jus.br/images/programas/movimento-pela-conciliacao/arquivos/ ARTIGO\%20Adolfo_MEDIACAO_CONCILIACAO_FEV_20111.pdf>. Acesso em: 03 abr. 2016.

BRASIL. Tribunal Regional do Trabalho da $2^{a}$ Região. Ementa de decisão que negou provimento ao pedido sobre escolha de árbitro. Recurso ordinário n 8972120135020 SP 00008972120135020445 A28. Órgão gestor de mão de obra do Porto de Santos e Marcos César dos Santos. Relator: Nelson Nazar. 19 de fev. de 2014. Disponível em: < http://trt2.jusbrasil.com.br/jurisprudencia/25001118/recurso-ordinario-ro-8972120135020-sp00008972120135020445-a28-trt-2>. Acesso em: 29 jul. 2016.

BRASIL. Tribunal Superior do Trabalho. Ementa de decisão que deu provimento a pedido de reconhecimento de termo de conciliação lavrado. Recurso de revista $n^{\circ} 18165320115040403$. Ete engenharia de telecomunicações e eletricidade Ltda, Daniel Ramos, Oi s/a e Alcatel-lucent Brasil s/a. Relator: Walmir Oliveira da Costa. 17 de fev. De 2016. Disponível em: < http: //tst.jusbrasil.com.br/jurisprudencia/307140214/recurso-de-revista-rr$18165320115040403>$. Acesso em: 29 jul. 2016.

BUENO, Cassio Scarpinella. Novo Código de Processo Civil anotado. São Paulo: Saraiva, 2015.

CLASTRES, Pierre. A arqueologia da violência. São Paulo: Cosac \& Naify, 2004.

CLASTRES, Pierre. A sociedade contra o Estado: investigações de antropologia política. Porto: Afrontamento, 1975.

FERREIRA, Tatiana Amaral Sanches Ferreira. A antropologia de Pierre Clastres em crônicas dos índios Guayaki: o que sabem os Aché, caçadores nômades do Paraguai. Revista de Antropologia Social dos Alunos do PPGAS-UFSCar, v. 3, n. 1, jan-jun., p. 375-383, 2011.

GRINOVER, Ada Pellegrini. Novas tendências do direito processual. Malheiros: São Paulo, 2008.

KLUNK, Luzia. O conflito e os meios de solução: reflexões sobre mediação e conciliação. In: SPLENGER, Fabiana Marion; SPLENGER NETO, Theobaldo (Orgs.) Mediação enquanto política pública: o conflito, a crise da jurisdição e as práticas mediativas. Santa Cruz do Sul: EDUNISC UNISC, 2012. p. 63-77.

MARASCA, Elisângela Nedel. Meios alternativos de solução de conflitos como forma de acesso à justiça e efetivação da cidadania. Revista Direito em Debate, ljuí, ano XV n 27, 28, janjun/jul-dez. 2007. p- 33-59. 
MELLO, Kátia Sento Sé; BAPTISTA, Bárbara Gomes Lupetti. Mediação e Conciliação no Judiciário: Dilemas e significados. Disponível em: <http://www.uff.br/ineac/sites/default/ files/mediacao-conciliacao--judiciario_dilemas_e_significados.pdf>. Acesso em: 03 abr. 2016.

NASCIMENTO, Amauri Mascaro. Curso de direito processual do trabalho. 25. ed. São Paulo: Saraiva, 2010.

RADCLIFFE-BROWN, Alfred Reginald. Estrutura e função na sociedade primitiva. Petrópolis: Vozes, 1881.

REIS, Ívano de Menezes; HOGEMANN, Edna Raquel; MACHADO, Consuêlo de Freitas. Arbitragem: noções essenciais - entendendo a Lei n ${ }^{\circ}$ 9307/96. Revista eletrônicada UCB, Brasília, p. 202252. Disponível em: <http://www.castelobranco.br/sistema/novoenfoque/files/04/REVISTA EELETRONICA_DE_DIREITO_DA_UCB-ARBITRAGEM_NOCOES_ESSENCIAIS.pdf> Acesso em: 20 maio 2016.

REIS, Marcos Aurélio; COUTINHO, Patrícia Martins Rodrigues. A prática da mediação e o acesso à justiça: por um Agir Comunicativo. Disponível em: <file:///C:/Users/User/Downloads /ARTIGOCIENTIFICO_MEDIACAOUNIEURO.pdf> Acesso em: 03 abr. 2016.

RODRIGUES, Amanda; THEMUDO, Thiago. Sociedades primitivas e direito contemporâneo: de que forma a justiça tribal pode nos ajudar a repensar a nossa justiça. Revista Brasileira de Políticas Públicas, Brasília, v. 5, nº 1, p. 302-316, jan/jun. 2015.

SILVA, Sílvio Maia da. O novo Código de Processo Civil e a mediação como meio de solução de controvérsias. Disponível em: <http://www5.tjba.jus.br/conciliacao/images/stories/O_Novo_ CPC_e_a_Medicao.pdf> Acesso em: 24 maio 2016.

SOUZA, Victor Roberto Corrêa de. O novo código de processo civil brasileiro e a audiência de conciliação ou mediação como fase inicial do procedimento. In: MALLART, Adriana Silva; DIZ, Jamile Bergamaschine Mota; GAGLIETTI, Mauro José. (Orgs.) Justiça mediática e preventiva. Florianópolis: CONPEDI, 2015. p. 262.

Recebido em: 03/08/2016 / Aprovado em: 31/10/2016 